\title{
REVISTA PESQUISA BRASILEIRA EM CIÊNCIA DA INFORMAÇÃO E BIBLIOTECONOMIA - PBCIB: UM MAPEAMENTO TEMÁTICO DA PRODUÇÃO CIENTÍFICA À LUZ DA ANÁLISE DE CONTEÚDO
}

\author{
REVISTA PESQUISA BRASILEIRA EM CIÊNCIA DA INFORMAÇÃO \\ E BIBLIOTECONOMIA - PBCIB: UN MAPEAMIENTO TEMÁTICO \\ DE LA PRODUCCIÓN CIENTÍFICA A LA LUZ DEL ANÁLISIS DE \\ CONTENIDO
}

\author{
Isa Maria Freire - isa@dci.ccsa.ufpb.br \\ Doutora em Ciência da Informação \\ Professora do Programa de Pós-Graduação em Ciência da Informação da \\ Universidade Federal da Paraíba, UFPB \\ Alexandre Pereira Souza - alex.alembert@gmail.com \\ Mestrando do Programa de Pós-Graduação em Ciência da Informação da \\ Universidade Federal da Paraíba, UFPB
}

\begin{abstract}
Resumo
Refere-se ao mapeamento temático da produção científica registrada no periódico eletrônico de referência Pesquisa Brasileira em Ciência da Informação e Biblioteconomia - PBCIB, a partir das informações contidas nos resumos publicados entre 2006-2008. O artigo originou-se de pesquisa sobre Mapeamento da Produção Científica do Periódico Eletrônico PBCIB. Para realização da pesquisa foi feita a identificação temática dos 194 resumos indexados a partir dos eixos temáticos da revista. Finalizada essa etapa os resumos foram dispostos em um corpus de análise e categorizados de acordo com suas respectivas temáticas. A pesquisa define-se por seu caráter exploratório-descritivo com abordagem quali-quantitativa, utilizando como técnica a análise de conteúdo para mapear os resumos e categorizá-los, assinalando assim as características e abrangência da revista. De acordo com os dados da pesquisa, a PBCIB cumpre sua função de periódico de referência direcionando seus usuários a conteúdos nas áreas da Ciência da Informação e Biblioteconomia, oferecendo um serviço relevante para as áreas cujos campos de pesquisa vêm apresentando crescente produção científica no Brasil. Apresenta sugestões que podem contribuir para a otimização dos serviços prestados, sugerindo uma análise completa do periódico com o objetivo de proporcionar maior consistência, precisão e visibilidade da revista na comunidade acadêmica.
\end{abstract}

Palavras-chave 
Produção científica. Comunicação científica. Periódicos eletrônicos. Análise de conteúdo. Ciência da Informação. Biblioteconomia.

\section{INTRODUÇÃO}

Este artigo apresenta os resultados de pesquisa realizada com o objetivo de analisar o resultado de buscas temáticas na revista eletrônica Pesquisa Brasileira em Ciência da Informação e Biblioteconomia (PBCIB), periódico secundário nessas áreas do conhecimento científico, no Brasil.

A revista $\mathrm{PBCIB}$ disponibiliza resumos de artigos científicos publicados em periódicos primários, bem como os sumários das revistas indexadas, resumos de monografias, dissertações e teses da graduação e pós-graduação, resenhas e recensões nas áreas de Ciência da Informação e Biblioteconomia. Nesse contexto, representa um modo de acesso rápido e prático no que diz respeito à recuperação da informação científica, nessas áreas do conhecimento. Destaca-se que o periódico científico secundário possui a característica de fonte de informação relevante para a pesquisa, além de ser um indicador da produção científica publicada por periódicos científicos eletrônicos primários.

Contextualizado o tema, o problema e a justificativa abordados, a presente pesquisa teve como objetivo analisar a produção científica publicada no periódico eletrônico PBCIB, entre 2006 e 2008. Para a realização de nosso objetivo identificamos quais periódicos estavam indexados pela PBCIB a fim de revelar a sincronia entre o escopo da revista e as temáticas mais relevantes sob a ótica da recuperação de informações contidas nos documentos indexados.

$\mathrm{Na}$ intenção de estabelecer uma sequência coerente entre a abordagem do tema o os objetivos propostos, inserimos no referencial teórico alguns tópicos relacionados ao campo da Ciência da Informação e Biblioteconomia, com ênfase no periódico de referência eletrônico, bem como na produção e comunicação científica, perpassando pela teia metodológica e considerações finais.

\section{PRODUÇÃO CIENTÍFICA: o contexto do periódico eletrônico}

A importância de se estudar a produção científica repousa na tese desta manter uma relação direta com o desenvolvimento científico-tecnológico e econômico de um país. Meadows (2001) ressalta que existe uma íntima relação entre crescimento científico e crescimento econômico de um país, segundo a premissa de que quem mais produz Ciência e Tecnologia é quem mais avança no processo de desenvolvimento global. Nessa perspectiva, é possível afirmar que os investimentos em ciência e tecnologia, são sem sombra de dúvidas rentáveis em relação às descobertas úteis e importantes para a sociedade. Por produção científica, Lourenço (1997) entende

Toda produção documental sobre um determinado assunto de interesse de uma comunidade científica específica, que contribui para o desenvolvimento da ciência e para a abertura de novos 
horizontes de pesquisa, não importando o suporte em que está veiculada.

O conhecimento científico só pode ser produzido mediante a evolução e consolidação da ciência. Assim, é possível conceituar produção científica como sendo todo conhecimento produzido no âmbito acadêmico pautado nas artes do método científico, sendo socializado, a partir de sua comunicação e publicação.

A produção científica constitui-se em uma análise mais ampla num instrumento de prestação de contas, uma vez que permite a universidade mostrar à sociedade, os resultados, a pertinência e a relevância de suas ações. É, também, o reflexo do desempenho docente e discente, nas atividades indissociáveis de ensino, pesquisa e extensão, traduzindo o esforço institucional da construção de seu capital intelectual. Destarte, a análise da produção científica além de ampliar o conhecimento sobre as diversas áreas do saber, possibilita o mapeamento de novas tendências e estudos no campo da ciência.

A produção científica faz parte de um grande sistema social que é a ciência. A ciência necessita ser considerada como um amplo sistema social, no qual uma de suas funções é disseminar conhecimentos. Sua segunda função é assegurar a preservação de padrões e, a terceira, é atribuir crédito e reconhecimento para aqueles cujos trabalhos têm contribuído para o desenvolvimento das idéias em diferentes campos (MACIAS CHAPULA, 1998)

Concernente à produção científica, Latour (2000) lembra que a ciência não é apenas conhecimento publicado. Para ele, o pesquisador, ao desenvolver uma pesquisa, sugere um enunciado científico, que poderá ser utilizado ou não por outros cientistas. Dessa forma, por meio da pesquisa metódica e sistemática, a ciência é construída de maneira coletiva, com o "objetivo [de] assumir um consenso no julgamento racional, sobre o maior número de áreas e tão extensas quanto possível" (ZIMAN, 1979). Por esse motivo, é necessário, o compartilhamento do conhecimento científico gerado na pesquisa, registrado e estruturado, por meio de publicação especializada.

\subsection{Periódicos Científicos Primários}

Antes do surgimento dos periódicos científicos, as informações sobre ciência eram veiculadas em folhetins, volantes e jornais cotidianos. Desde a invenção da imprensa até o século XVII era comum a circulação de jornais e folhetins, entretanto, quando se fazia necessário a comunicação de um conhecimento mais especializado, este era realizado por meio de correspondências entre os cientistas e/ou através de atas ou memórias das reuniões científicas. De acordo com Stumpf (1996, p. 1):

A correspondência pessoal foi o primeiro meio utilizado pelos cientistas para a transmissão de suas idéias. As cartas eram enviadas pelos homens de ciência a seus amigos para relatar suas descobertas mais recentes e circulavam entre pequenos grupos de interessados que as examinavam e discutiam criticamente. Sua divulgação era tão direcionada, uma vez que seus autores quase nunca as enviavam para aqueles que podiam 
refutar suas teorias ou rejeitar seus experimentos. Por serem muito pessoais, lentas para a divulgação de novas idéias e limitadas a um pequeno círculo de pessoas, essas "dissertações epistolares", [...] não se constituíram no método ideal para a comunicação do fato científico e das teorias.

As atas ou memórias eram constituídas por transcrições das descobertas que eram relatadas durante as reuniões de uma sociedade e depois impressas de forma resumida para servirem de fonte de consulta e referência aos membros dessas sociedades. Eles participavam regularmente desses encontros (alguns secretos), onde realizavam experimentos de pesquisas, avaliavam os resultados e discutiam sobre temas filosóficos e científicos. É a partir dessas correspondências e atas que surgem as publicações científicas.

O surgimento dos periódicos científicos não descartou a existência desses dois tipos de registros. No entanto, houve uma redefinição de papéis entre os diversos canais de divulgação da ciência, onde a correspondência tomou um caráter de comunicação pessoal entre os cientistas, e as atas, conhecidas também como memórias ou anais, passaram a se organizar em um documento de registro dos trabalhos apresentados em reuniões científicas e profissionais.

Embora não se tenha uma única definição para periódico eletrônico, adotamos alguns conceitos pertinentes à proposta desta pesquisa. Assim, compreendemos que o periódico científico eletrônico é aquela publicação arbitrada criada, produzida e editada em hipertexto com versão única digital difundida pela Internet, com características editoriais que se apegam estritamente às normas de qualquer revista acadêmica ou científica (ORNELAS; ARROYO, 2006). No pensamento de Biojone (2003), o que caracteriza um periódico desse gênero é ter todas as suas fases realizadas totalmente em meio digital (da editoração até a distribuição). Sua distribuição pode estar disponível em suportes como: CD-ROM, ou Internet.

De acordo com Dias (2003), o periódico científico eletrônico é um produto tecnológico oriundo das atividades de comunicação da ciência, cuja finalidade precípua é a divulgação de informações para sua comunidade alvo (pesquisadores, docentes e dicentes). Nessa perspectiva, os periódicos eletrônicos acompanharam a evolução tecnológica e o desenvolvimento do sistema de hipertextos pela web, oferecendo soluções para alguns impasses como, por exemplo, o aumento exponencial e contínuo do espaço físico das bibliotecas. Meadows (2001) observou de maneira positiva a transformação do conceito de publicação no ambiente eletrônico, acreditando no aumento do domínio do autor e na redução do controle do editor, ou seja, o processo de publicação torna-se menos unificado.

É possível perceber que a transição entre os suportes impresso e eletrônico - processo que aponta para a supremacia do eletrônico em curto prazo - não foge completamente aos modelos tradicionais ainda vigentes no financiamento de revistas científicas. De acordo com Briquet de Lemos (2005), são eles:

a) Pagamento de assinatura e, eventualmente, pagamento da publicação pelo autor; 
b) Pagamento da publicação pelo autor e acesso livre;

c) Custeio pelas instituições ou com apoio governamental.

Entretanto, além das iniciativas tomadas pelas universidades e órgãos de fomento à pesquisa, para formar alianças e disponibilizar aos pesquisadores os periódicos eletrônicos de acesso restrito, iniciativas de âmbito internacional também estão sendo adotadas para romper as barreiras econômicas impostas pelo sistema editorial e defender a livre disseminação dos resultados de pesquisas científicas financiadas com recursos públicos. São os periódicos de acesso livre, os repositórios, arquivos abertos e agregadores de uso gratuito.

Em consonância com as tendências de acesso livre, uma pesquisa realizada por Meirelles (2005), na Internet e na literatura, revelou que o único sistema no Brasil que "atende as necessidades de gestão de um periódico cientifico em todas as etapas do processo editorial, além de operar dentro da filosofia de acesso livre a informação e de intercambio de dados através do OAlPMH, é o Sistema Eletrônico de Editoração de Revistas" (MEIRELLES, 2005, p.200). O SEER faz parte de uma nova geração de sistemas de gerenciamento de periódicos científicos, e no Brasil surgiu como modelo alternativo de publicação do conhecimento científico com vistas a ampliar o acesso, a preservação e o impacto da busca de informação e dos resultados daí provenientes. Segundo Márdero Arellano, Santos e Fonseca (2005),

Esta ferramenta contempla ações primordiais à automação das atividades de editoração de periódicos científicos, permitindo completa autonomia na tomada de decisões sobre o fluxo editorial, a publicação e o acesso por parte do editor; ele define as etapas do processo editorial, de acordo com a política definida pela revista, mas dispondo de assistência e registro on-line em todas as fases do sistema de gerenciamento. Na etapa de submissão, o sistema disponibiliza um espaço para comunicação com o editor e permite também o acompanhamento da avaliação e editoração do trabalho.

Sob este prisma, o SEER é considerado atualmente uma solução prática e econômica, que atende as necessidades de redução de custos e eficiência dos processos editoriais dos periódicos científicos brasileiros. O sistema conta com um Manual de Instalação, disponibilizado no site do projeto. Com ele espera-se diminuir o número de pedidos de suporte técnico por parte das equipes de informática das revistas (MÁRDERO ARELLANO; SANTOS; FONSECA, 2005).

\subsection{O Periódico Eletrônico Secundário: a Revista PBCIB}

As fontes de informações secundárias caracterizam-se por conter informações sobre documentos primários, ou seja, não são originais e basicamente citam, revisam e interpretam os trabalhos originais. Em suma, podese inferir que as fontes secundárias de informação são, na verdade, um meio de organizar os documentos primários guiando o usuário até o documento original. No contexto das fontes de informação é possível identificar diversos tipos de obras, como por exemplo: abstracts, índices, resumos, sumários, dicionários e inclusive os periódicos secundários ou de referência. $O$ periódico eletrônico 
secundário pode ser compreendido como aquele que proporciona acesso a citações e resumos de artigos, monografias, dissertações, teses e sumários correntes, direcionando o usuário as fontes primárias na integra (SOUZA, 2010).

De acordo com (FREIRE et al., 2007) a revista PBCIB se caracteriza como um serviço de resumos que adotou a forma de periódico secundário. A PBCIB tem como fontes as revistas científicas brasileiras disponíveis na Internet, nas áreas de Ciência da Informação e Biblioteconomia. Pois embora realize um serviço de resumos, o periódico Pesquisa Brasileira em Ciência da Informação e Biblioteconomia pode ser considerado uma publicação secundária, que de acordo com Pinheiro (2006), constituem fontes ou recursos de informações originadas em outras fontes, denominadas primárias. Atherton (1977 apud PINHEIRO, 2006), nos esclarece que em um periódico secundário a informação é representada e "raramente serve como substituto do documento original", portanto, deve ser organizada e detalhada de modo que possibilite ao usuário localizar a informação desejada na íntegra, no documento original. Destarte, por circular em períodos regulares este tipo de serviço de publicação de resumos é considerado como um periódico, sendo de caráter secundário. É nesses termos, por apresentar periodicidade semestral, e considerando seu registro no International Standard Serial Number (ISSN) ${ }^{1}$, que definimos a revista Pesquisa Brasileira em Ciência da Informação e Biblioteconomia como um periódico científico secundário.

Portanto, atende aos objetivos e características de uma publicação secundária e, no contexto da Sociedade da Informação, reveste-se da atualidade das Tecnologias de Informação e Comunicação (TIC's), tanto assumindo a forma eletrônica quanto disseminando informações disponíveis na Internet/Web (PINHEIRO, 2006).

A revista PBCIB está direcionada aos temas estudados pelo Grupo de Pesquisa (CNPq) Informação e Inclusão Social, liderado pelos professorespesquisadores Isa Maria Freire e Gustavo Henrique de Araujo Freire. Em seu cabeçalho, a revista tem descrito o estritamente necessário para situar o usuário em relação à revista: título, periodicidade e titularidade.

i. Quanto à periodicidade a revista é publicada semestralmente, a partir do primeiro semestre de 2006;

ii. Em relação à Política de acesso público, a revista proporciona acesso livre a todo seu;

iii. Conteúdo, com o intuito de tornar amplo e gratuito o acesso à pesquisas e promover um maior intercâmbio de conhecimento.

\footnotetext{
${ }^{1}$ Número Internacional Normalizado para Publicações Seriadas, identificador do título de uma publicação seriada, tornando-o único e definitivo. Seu uso é definido pela norma técnica internacional da International Standards Organization ISO 3297. O ISSN é operacionalizado por uma rede internacional, e no Brasil o Instituto Brasileiro de Informação em Ciência e Tecnologia IBICT atua como Centro Nacional dessa rede.
} 
Esta política corresponde aos princípios de publicação do patrocinador da revista no período $2006 / 2008^{2}$, o Instituto Brasileiro de Informação em Ciência e Tecnologia - IBICT, que apoiou a publicação com a tecnologia do SEER e aceitou o desafio de desenvolver sua aplicação a um novo formato de publicação eletrônica. O que foi feito com competência e criatividade por Ramón M. S. da Fonseca e pelos demais membros da Equipe SEER.

Os traçados e limites do universo documental inserido na PBCIB são informados a partir das seções específicas da revista, a saber: apresentação, editorial, resumos de artigos científicos, sumários correntes das revistas indexadas monografias, dissertações e teses da graduação e pós-graduação, resenhas, recensões.

Por fim, há ainda informação sobre o responsável pela publicação, o Grupo de Pesquisa Informação e Inclusão social, atualmente certificado pela UFPB, que tem como objetivos:

a) desenvolver metodologias para inclusão digital através de uma ação de informação em parceria com educadores, tanto da rede de ensino superior quanto da rede pública de ensino básico;

b) promover 0 desenvolvimento de competências em tecnologias intelectuais e digitais de informação;

c) contribuir para inclusão social através de uma ação em parceria com programas governamentais existentes;

d) contribuir para o desenvolvimento do campo científico da informação.

Estes elementos constituem, pois, o propósito e o objetivo, a organização e a política que orientam a equipe responsável e, conseqüentemente, o formato da revista. Quanto ao conteúdo, somos guiados pela temática descrita na página do Grupo de Pesquisa, no Diretório do Conselho Nacional de Pesquisa - CNPq (http://dgp.cnpq.br/diretorioc/), a saber:
i. Informação e inclusão social
ii. Competências em informação
iii. Identidade cultural e inclusão digital
iv. Representação, Gestão e Tecnologia da Informação
v. Estrutura e fluxo da informação.

A estas temáticas acrescentaram-se as áreas de Ciência da Informação e Biblioteconomia, incluídas no próprio título da revista, o que nos permite indexar assuntos como epistemologia, sociologia da informação, formação profissional, educação continuada e responsabilidade social no campo científico, entre outras. Os temas se ampliam e diversificam a partir da própria visão que cada indexador (denominado Editor $\mathrm{Ad} \mathrm{Hoc}$ ) tem sobre os assuntos abordados na PBCIB, e que se traduz na grande variedade de descritores de busca, transladados dos documentos originais.

\footnotetext{
${ }^{2}$ A revista foi transferida para o Portal de Periódicos da UFPB, através de um Projeto de Pesquisa apoiado pelo Programa Institucional Brasileiro de Iniciação Científica - PIBIC da UFPB, onde o Grupo de Pesquisa (CNPq) Informação e Inclusão Social se encontra localizado. Disponível em: http://periodicos.ufpb.br/ojs2/index.php/pbcib/index.
} 


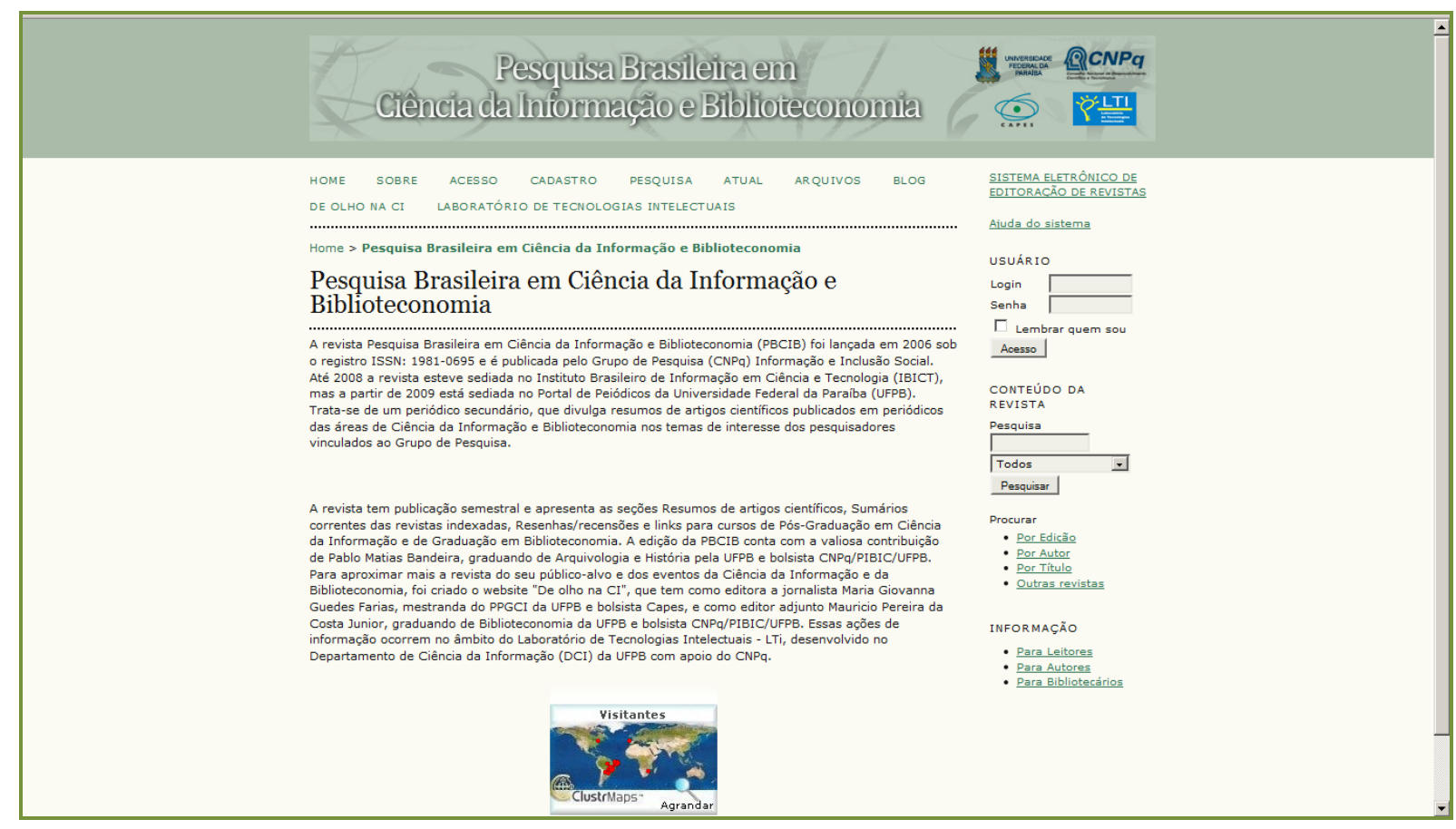

Figura 1 Página principal da revista PBCIB.

Fonte: Disponível em: http://periodicos.ufpb.br/ojs2/index.php/pbcib/index.

\section{PERCURSO METODOLÓGICO}

A pesquisa configura-se como exploratório-descritiva, com abordagem quantitativa e qualitativa, de cunho documental cujo principal objetivo é proporcionar maior familiaridade com o problema, com vistas a torná-lo explícito descrevendo características de determinada população ou fenômeno (GIL, 1999). Para validar este trabalho, adotamos a análise de conteúdo de Bardin (2004) no sentido de legitimá-la, uma vez que esta técnica possibilitou a mensuração dos dados que compõem o corpus de análise desta pesquisa.

Nosso campo de estudo foi constituído pela produção científica publicada no periódico eletrônico (PBCIB), que disponibiliza citações, resumos de artigos, teses e dissertações, sumários correntes da produção científica nas áreas de Ciência da Informação e Biblioteconomia, em níveis de graduação e pósgraduação, focalizando temas de Informação e Inclusão Social.

A interface de pesquisa da PBCIB é autoexplicativa, trazendo os campos a serem preenchidos. Em nossa pesquisa, optamos por combinar as categorias inserindo-as no campo pesquisar termo, com suas temáticas afins no campo área de conhecimento. 


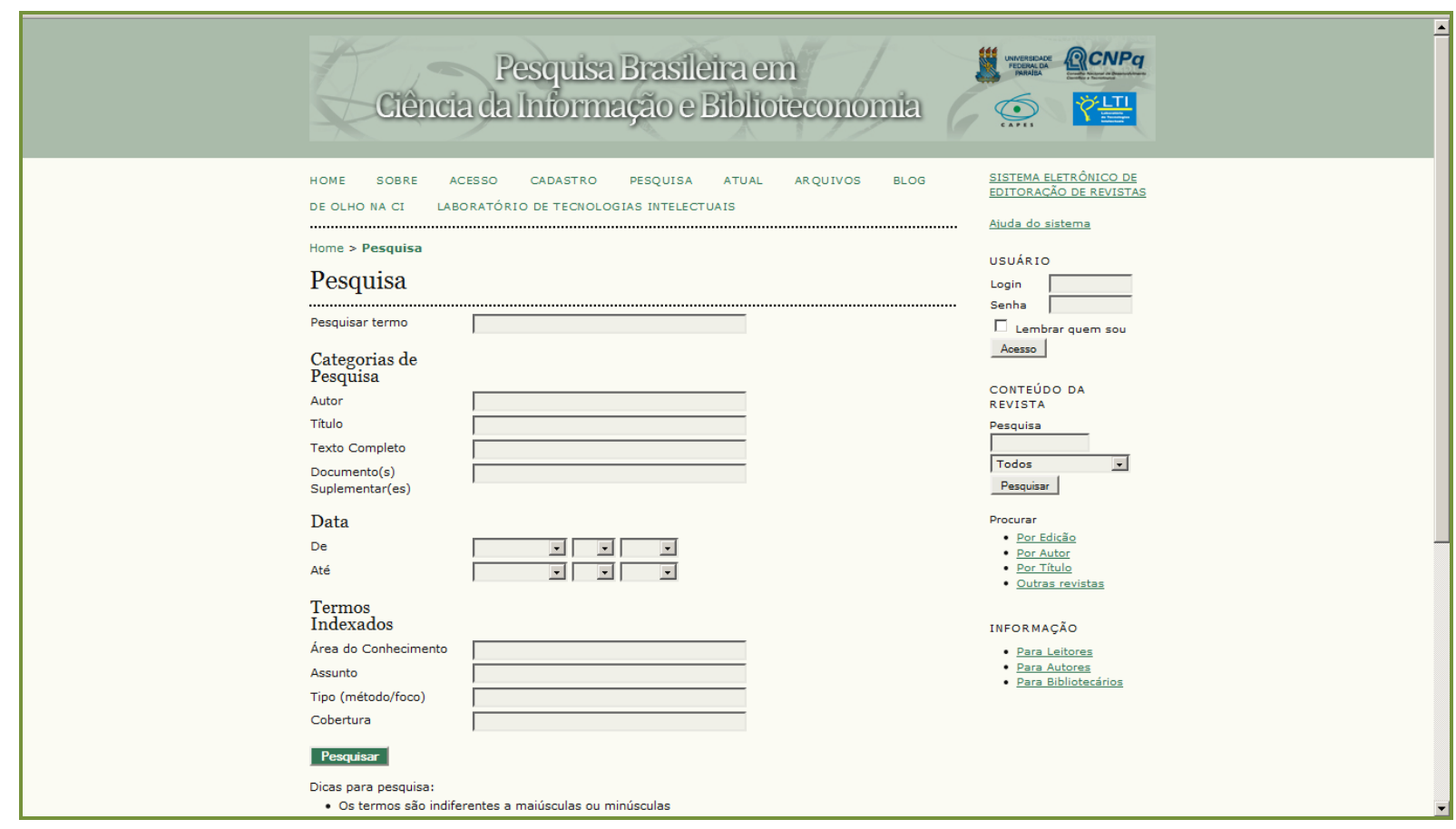

Figura 2 Interterface de pesquisa da revista PBCIB.

Fonte: Disponível em: http://periodicos.ufpb.br/ojs2/index.php/pbcib/search

\section{$4 \quad$ RESULTADOS DA PESQUISA}

Nesta seção, estão representados os dados sobre os resumos recuperados por cada um dos termos usados, na busca específica realizada na PBCIB. Tal procedimento foi executado a priori, com a elaboração de tabelas que explicitam a quantidade de resumos recuperados pelos respectivos termos de busca. Para os cálculos utilizou-se a operação matemática que relaciona dois valores de uma grandeza $A$, com dois valores de uma grandeza $B$, denominada regra de três simples, representada pela técnica $(\mathrm{a} 1 / \mathrm{a} 2=\mathrm{b} 1 / \mathrm{b} 2)$. Onde:

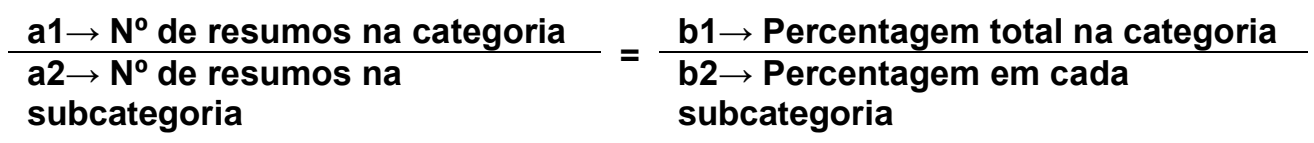

$\mathrm{Na}$ definição das categorias e subcategorias estabelecidas para esse estudo foram utilizados dois critérios. As categorias principais foram estabelecidas a partir das temáticas estudas pelo grupo de pesquisa, informação e inclusão social cadastrado no diretório do (CNPq), as subcategorias por sua vez foram constituídas pela análise de diversos descritores relacionados aos temas principais.

A seguir, apresentamos as tabelas elaboradas com intuito de subsidiar a análise feita sobre os resumos recuperados na PBCIB, explicitando assim, dois fatores de suma importância para a compreensão de nosso estudo.

1) O número de resumos recuperados por categoria. 
2) O número de resumos recuperados por subcategoria e seu percentual correspondente.

\subsection{Categoria Informação}

A Tabela 1, a seguir, apresenta a quantidade de resumos recuperados nas cinco subcategorias usadas para descrever a categoria Informação.

Tabela 1 Resumos recuperados: categoria Informação

\begin{tabular}{l|c|c}
\hline $\begin{array}{c}\text { Informação: } \\
\text { Subcategorias }\end{array}$ & $\begin{array}{c}\text { No de resumos por } \\
\text { subcategorias }\end{array}$ & $\begin{array}{c}\text { Percentagem por } \\
\text { subcategoria }\end{array}$ \\
\hline Informação para negócios & 5 & 19 \\
\hline Fluxo de informação & 4 & 15 \\
\hline Acesso livre [à informação] & 9 & 33 \\
\hline Construção do conhecimento & 8 & 29 \\
\hline Organização da informação & 1 & 4 \\
\hline TOTAL & $\mathbf{2 7}$ & $\mathbf{1 0 0 \%}$ \\
\hline
\end{tabular}

Fonte: Pesquisa direta, 2009.

Como podemos observar, as subcategorias, Construção do conhecimento e Acesso livre [à informação] apresentam os maiores índices de recuperação, totalizando $29 \%$ e $33 \%$ respectivamente. Já as subcategorias, Informação para negócios e Fluxo de informação recuperaram 19\% e 15\% respectivamente, enquanto Organização da Informação representa 4\% do material recuperado. Do exposto, pode-se inferir que a maior parte dos documentos recuperados na categoria Informação versa sobre os assuntos acerca de construção do conhecimento e acesso livre [à informação], demonstrando a pertinência e consistência dos resumos indexados, em relação à proposta temática da revista.

\subsection{Categoria Inclusão Social}

A seguir, apresentamos a Tabela 2 com a quantidade de resumos recuperados, nas subcategorias usadas para descrever a categoria Inclusão social.

Tabela 2 Resumos recuperados: categoria Inclusão Social

\begin{tabular}{l|c|c}
\hline $\begin{array}{c}\text { Inclusão social: } \\
\text { Subcategorias }\end{array}$ & $\begin{array}{c}\text { No de resumos por } \\
\text { subcategorias }\end{array}$ & $\begin{array}{c}\text { Percentagem por } \\
\text { subcategoria }\end{array}$ \\
\hline Inclusão digital & 13 & 50 \\
\hline Cidadania & 3 & 11 \\
\hline Educação & 9 & 35 \\
\hline Políticas públicas & 1 & 4 \\
\hline \multicolumn{1}{c|}{ TOTAL } & $\mathbf{2 6}$ & $\mathbf{1 0 0}$ \\
\hline
\end{tabular}

Fonte Pesquisa direta, 2009. 
Observa-se, na Tabela 2, que a maior parcela dos resumos recuperados é representada pela subcategoria Inclusão digital, com 50\% dos resumos recuperados. A subcategoria Educação detém uma parcela de $35 \%$ e a de Cidadania $11 \%$ dos resumos recuperados, o que demonstra a pertinência e consistência da indexação, considerando-se a temática definida pela revista.

\subsection{Categoria Competências em Informação}

A seguir, apresentamos a Tabela 3 com a quantidade de resumos recuperados nas subcategorias usadas para descrever a categoria Competências em informação.

Tabela 3 Resumos recuperados: categoria Competências em Informação

\begin{tabular}{c|c|c}
\hline $\begin{array}{c}\text { Competências em informação: } \\
\text { Subcategorias }\end{array}$ & $\begin{array}{c}\text { No de resumos por } \\
\text { subcategorias }\end{array}$ & $\begin{array}{c}\text { Percentagem por } \\
\text { subcategoria }\end{array}$ \\
\hline Tecnologia da informação & 13 & 52 \\
\hline Habilidades em informação & 3 & 12 \\
\hline Formação profissional & 9 & 36 \\
\hline TOTAL & $\mathbf{2 5}$ & $\mathbf{1 0 0}$ \\
\hline
\end{tabular}

Fonte Pesquisa direta, 2009.

Em relação ao tema Competências em informação, observa-se que a subcategoria Tecnologia da informação apresenta um índice de recuperação de $52 \%$. A subcategoria Formação profissional recupera $36 \%$ dos resumos, enquanto Habilidades em informação, responde por $12 \%$ dos resumos recuperados. Resultado que reflete o segundo objetivo do Grupo de pesquisas, Informação e inclusão social certificado pela UFPB, a saber: promover o desenvolvimento de competências em tecnologias intelectuais e digitais de informação.

\subsection{Categoria Identidade Cultural}

A seguir, apresentamos a tabela com a quantidade de resumos recuperados nas subcategorias usadas para descrever a categoria Identidade cultural.

Tabela 4 Resumos recuperados: categoria Identidade Cultural

\begin{tabular}{l|c|c}
\hline $\begin{array}{c}\text { Identidade cultural: } \\
\text { Subcategorias }\end{array}$ & $\begin{array}{c}\text { No de resumos por } \\
\text { subcategorias }\end{array}$ & $\begin{array}{c}\text { Percentagem por } \\
\text { subcategoria }\end{array}$ \\
\hline Identidade social & 2 & 22 \\
\hline Memória & 1 & 11 \\
\hline Informação & 6 & 67 \\
\hline \multicolumn{1}{c|}{ TOTAL } & $\mathbf{9}$ & $\mathbf{1 0 0}$ \\
\hline
\end{tabular}

Fonte Pesquisa direta, 2009. 
A subcategoria Informação apresenta o maior o índice de recuperação, equivalente a $67 \%$ mas devemos reconhecer que o termo se torna redundante por se tratar de qualificativo da própria categoria (Competências em informação). Nesse sentido, a subcategoria Identidade social, com $22 \%$ dos resumos recuperados, é a que melhor representa essa categoria que qualifica uma das linhas de pesquisa do Grupo de Pesquisa (CNPq) responsável pela edição da revista ${ }^{3}$.

\subsection{Categoria Inclusão Digital}

A seguir, apresentamos a Tabela 5, com a quantidade de resumos recuperados nas subcategorias usadas para descrever a categoria Inclusão digital.

Tabela 5 Resumos recuperados: categoria Inclusão Digital

\begin{tabular}{l|c|c}
\hline $\begin{array}{c}\text { Inclusão digital: } \\
\text { Subcategorias }\end{array}$ & $\begin{array}{c}\text { No de resumos por } \\
\text { subcategorias }\end{array}$ & $\begin{array}{c}\text { Percentagem por } \\
\text { subcategoria }\end{array}$ \\
\hline Tecnologia da informação & 6 & 20 \\
\hline Sociedade da informação & 9 & 30 \\
\hline Internet & 2 & 7 \\
\hline Inclusão social & 11 & 36 \\
\hline Software livre & 2 & 7 \\
\hline \multicolumn{1}{c|}{ TOTAL } & $\mathbf{3 0}$ & $\mathbf{1 0 0}$ \\
\hline
\end{tabular}

Fonte Pesquisa direta, 2009.

Se na categoria Inclusão social a subcategoria Inclusão digital alcançava $50 \%$ dos resumos recuperados, aqui a subcategoria Inclusão social é responsável por $36 \%$ dos resumos recuperados, um pouco mais do que a subcategoria Sociedade da informação. Nesta categoria, a subcategoria Tecnologias da informação totalizou $20 \%$ dos resumos recuperados, menos do que obteve na categoria Competências em informação.

\subsection{Categoria Representação}

A seguir, apresentamos na Tabela 6 , a quantidade de resumos recuperados nas subcategorias usadas para descrever a categoria Representação.

Nesta tabela, observa-se que a subcategoria Metadados totaliza 34\% dos resumos, enquanto Linguagens documentárias e Tesauro apresentam o mesmo percentual de $22 \%$ dos resumos recuperados. Destarte, deve-se ressaltar que o termo Representação não aparece na delimitação temática da revista.

3 Informação e Inclusão Social. 
Tabela 6 Resumos recuperados: categoria Representação

\begin{tabular}{l|c|c}
\hline \multicolumn{1}{c|}{$\begin{array}{c}\text { Representação: } \\
\text { Subcategorias }\end{array}$} & $\begin{array}{c}\text { No de resumos por } \\
\text { subcategorias }\end{array}$ & $\begin{array}{c}\text { Percentagem } \\
\text { por } \\
\text { subcategoria }\end{array}$ \\
\hline Metadados & 3 & 34 \\
\hline Linguagens documentárias & 2 & 22 \\
\hline Mapas conceituais & 1 & 11 \\
\hline Tesauros & 2 & 22 \\
\hline $\begin{array}{l}\text { Sistema de Recuperação da } \\
\text { informação }\end{array}$ & 1 & 11 \\
\hline \multicolumn{1}{c|}{ TOTAL } & $\mathbf{9}$ & $\mathbf{1 0 0}$ \\
\hline
\end{tabular}

Fonte Pesquisa direta, 2009.

\subsection{Categoria Gestão}

A seguir, apresentamos a tabela com a quantidade de resumos recuperados nas cinco subcategorias usadas para descrever a categoria Gestão.

Tabela 7 Resumos recuperados: categoria Gestão

\begin{tabular}{l|c|c}
\hline \multicolumn{1}{c|}{$\begin{array}{c}\text { Gestão: } \\
\text { Subcategorias }\end{array}$} & $\begin{array}{c}\text { No de resumos } \\
\text { por subcategorias }\end{array}$ & $\begin{array}{c}\text { Percentagem por } \\
\text { subcategoria }\end{array}$ \\
\hline Documentos & 2 & 5 \\
\hline Bibliotecas & 18 & 51 \\
\hline Capital social & 2 & 5 \\
\hline Competências em informação & 2 & 5 \\
\hline Informação científica & 12 & 34 \\
\hline \multicolumn{1}{c|}{ TOTAL } & $\mathbf{3 6}$ & $\mathbf{1 0 0}$ \\
\hline
\end{tabular}

Fonte: Pesquisa direta, 2009.

Ao analisarmos a categoria Gestão, observamos que a subcategoria Bibliotecas detém $51 \%$ dos resumos recuperados, mostrando a presença da produção de Biblioteconomia nos resumos indexados pela revista. Para a subcategoria Informação científica houve um índice de 34\% de recuperação. Observou-se durante o processo de recuperação que a expressão gestão de bibliotecas recuperou mais resumos do que gestão de unidades de informação: dessa forma podemos inferir que apesar de se preconizar a substituição do termo bibliotecas por unidades de informação, o primeiro ainda possui ampla utilização.

\subsection{Categoria Tecnologia da Informação}

A seguir, apresentamos a tabela com a quantidade de resumos recuperados nas subcategorias usadas para descrever a categoria Tecnologia da informação. 
Tabela 8 Resumos recuperados: categoria Tecnologia da Informação

\begin{tabular}{l|c|c}
\hline $\begin{array}{c}\text { Tecnologia da informação: } \\
\text { Subcategorias }\end{array}$ & $\begin{array}{c}\text { № de resumos por } \\
\text { subcategorias }\end{array}$ & $\begin{array}{c}\text { Percentagem por } \\
\text { subcategoria }\end{array}$ \\
\hline Softwares & 4 & 12 \\
\hline Usabilidade & 12 & 34 \\
\hline Ensino à distância & 2 & 5 \\
\hline Recuperação da informação & 5 & 14 \\
\hline Bibliotecas digitais & 13 & 36 \\
\hline \multicolumn{1}{c}{ TOTAL } & $\mathbf{3 6}$ & $\mathbf{1 0 0}$ \\
\hline
\end{tabular}

Fonte: Pesquisa direta, 2009.

Na análise da categoria Tecnologia da informação observamos que há uma distribuição discreta entre as subcategorias, com ligeira predominância de Bibliotecas digitais. O índice obtido pela subcategoria Educação a distância é representativo da ainda pouca difusão dessa tecnologia educacional na área.

\subsection{Categoria Estrutura}

A seguir, apresentamos a tabela com a quantidade de resumos recuperados nas subcategorias usadas para descrever a categoria Estrutura.

Tabela 9 Resumos recuperados: categoria Estrutura

\begin{tabular}{l|c|c}
\hline $\begin{array}{c}\text { Estrutura: } \\
\text { Subcategorias }\end{array}$ & $\begin{array}{c}\text { No de resumos por } \\
\text { subcategorias }\end{array}$ & $\begin{array}{c}\text { Percentagem por } \\
\text { subcategoria }\end{array}$ \\
\hline Bibliotecas & 14 & 51 \\
\hline Redes de conhecimento & 2 & 7 \\
\hline Sociedade da informação & 6 & 20 \\
\hline Hipertexto & 2 & 7 \\
\hline Fluxo de informação & 3 & 15 \\
\hline \multicolumn{1}{c}{ TOTAL } & $\mathbf{2 7}$ & $\mathbf{1 0 0}$ \\
\hline
\end{tabular}

Fonte: Pesquisa direta, 2009.

Quanto à categoria Estrutura, observamos que os resultados obtidos pela subcategoria Bibliotecas, com o maior índice de resumos recuperados, Sociedade da informação, com 29\% e Fluxo de informação com, 15\% de resumos recuperados, demonstram que as bibliotecas são percebidas como locais de informação e que a própria sociedade em que vivemos está sendo abordada, na literatura da área, como estrutura de informação.

\subsection{Categoria Fluxo da Informação}

A seguir, apresentamos a tabela com a quantidade de resumos recuperados nas três subcategorias usadas para descrever a categoria Fluxo da informação. 
Tabela 10 Resumos recuperados: categoria Fluxo da Informação

\begin{tabular}{l|c|c}
\hline $\begin{array}{c}\text { Fluxo da informação: } \\
\text { Subcategorias }\end{array}$ & $\begin{array}{c}\text { № de resumos por } \\
\text { subcategorias }\end{array}$ & $\begin{array}{c}\text { Percentagem por } \\
\text { subcategoria }\end{array}$ \\
\hline Redes de informação & 2 & 50 \\
\hline Produção científica & 1 & 25 \\
\hline Gestão do conhecimento & 1 & 25 \\
\hline TOTAL & $\mathbf{4}$ & $\mathbf{1 0 0}$ \\
\hline
\end{tabular}

Fonte: Pesquisa direta, 2009.

Na categoria Fluxo da informação observa-se um índice de recuperação de $50 \%$ para a subcategoria Redes de informação, resultado obtido em virtude da interdisciplinaridade dos estudos sobre sociedade da informação, bibliotecas e redes e estrutura de fluxos de informação. As subcategorias Gestão do conhecimento e Produção científica recuperaram $25 \%$ dos resumos disponíveis.

\subsection{Categoria Ciência da Informação}

A seguir, apresentamos a tabela com a quantidade de resumos recuperados nas subcategorias usadas para descrever a categoria Ciência da informação.

Tabela 11 Resumos recuperados: categoria Ciência da Informação

\begin{tabular}{l|c|c}
\hline $\begin{array}{c}\text { Ciência da Informação: } \\
\text { Subcategorias }\end{array}$ & $\begin{array}{c}\text { No de resumos por } \\
\text { subcategorias }\end{array}$ & $\begin{array}{c}\text { Percentagem por } \\
\text { subcategoria }\end{array}$ \\
\hline Segurança da informação & 3 & 17 \\
\hline Perfil profissional & 6 & 34 \\
\hline Cognição situada & 4 & 22 \\
\hline Periódico científico & 4 & 22 \\
\hline Arquitetura da informação & 1 & 5 \\
\hline TOTAL & $\mathbf{1 8}$ & $\mathbf{1 0 0}$ \\
\hline
\end{tabular}

Fonte: Pesquisa direta, 2009.

Na categoria Ciência da informação o maior índice de recuperação é representado pela subcategoria Perfil profissional com 34\% de resumos recuperados, o que mostra uma associação entre a formação profissional e 0 campo científico da informação.

\subsection{Categoria Biblioteconomia}

A seguir, apresentamos a tabela com a quantidade de resumos recuperados nas três subcategorias usadas para descrever a categoria Biblioteconomia. 
Tabela 12 Resumos recuperados: categoria Biblioteconomia

\begin{tabular}{l|c|c}
\hline Subcategorias & $\begin{array}{c}\text { No de resumos por } \\
\text { subcategorias }\end{array}$ & $\begin{array}{l}\text { Percentagem por } \\
\text { subcategoria }\end{array}$ \\
\hline Biblioterapia & 6 & 35 \\
\hline Marketing & 2 & 12 \\
\hline Linguagem documentária & 3 & 18 \\
\hline Interdisciplinaridade & 2 & 12 \\
\hline Administração de bibliotecas & 4 & 23 \\
\hline \multicolumn{1}{c|}{ TOTAL } & $\mathbf{1 7}$ & $\mathbf{1 0 0}$ \\
\hline
\end{tabular}

Fonte Pesquisa direta, 2009.

$\mathrm{Na}$ categoria Biblioteconomia a subcategoria Biblioterapia representa $35 \%$ dos resumos recuperados, seguindo-se a subcategoria Administração de Bibliotecas. O índice demonstra um viés na indexação dos resumos, pois seria de se esperar que a subcategoria Administração de bibliotecas contemplasse o maior índice de recuperação de resumos.

\section{CONSIDERAÇÕES FINAIS}

O periódico de resumos, ou periódico secundário, tem sido reconhecido como canal de comunicação e difusão científica em virtude de sua praticidade por proporcionar a leitura das partes principais de um documento, e eficiência por fornecer acesso ao original na íntegra. Destarte, o periódico secundário cumpre o que preconizava Ranganathan ao recomendar: "poupe o tempo do leitor".

Partindo dessa premissa, podemos afirmar que o periódico de resumos surge com a proposta de dinamizar a divulgação de informações na comunidade científica, e poupar o tempo de cientistas e pesquisadores que necessitam de informações pontuais em um curto espaço de tempo. Naturalmente não substitui a busca pessoal e minuciosa dos pesquisadores, em cada periódico da área, sobre os temas de interesse para seus estudos e pesquisas, mas atende em nível satisfatório a uma primeira abordagem bibliográfica sobre temas específicos.

Observamos, na pesquisa, que a revista PBCIB indexa, além de resumos de artigos científicos publicados em periódicos eletrônicos, as próprias revistas e portais que proporcionam acesso integral ao documento, estas na seção Sumários correntes. Considerando nossa amostra na pesquisa, constituída por 194 resumos de artigos publicados em periódicos científicos, verificamos links para as revistas e portais, a saber: Encontros Bibli; Data Grama Zero; Informação \& Informação; Revista ACB de Biblioteconomia; Ciência da informação; Informação \& Sociedade: Estudos; Em Questão; Inclusão Social; Perspectivas em Ciência da Informação; Revista Brasileira de Biblioteconomia e Documentação; Revista Digital de Biblioteconomia e Ciência da Informação; Transinformação; 
Educação Temática Digital; Ponto de Acesso; Morpheus; Revista Eletrônica de Comunicação, Informação e Inovação em Saúde.

O mapeamento dos resumos a partir dos eixos temáticos apresentou 49 indexadores responsáveis pela recuperação desses 194 resumos, comprovando a pertinência das temáticas abrangidas pela PBCIB em relação ao conteúdo disponibilizado e seu escopo. De acordo com os dados da pesquisa, a PBCIB cumpre sua função de periódico de referência direcionando seus usuários a conteúdos nas áreas da ciência da informação e biblioteconomia, oferecendo um serviço relevante para as áreas da Ciência da Informação e Biblioteconomia, campos de pesquisa que vêm apresentando crescente produção científica no Brasil.

O mérito desse estudo repousa na ação de oferecer um panorama geral e ao mesmo tempo específico do periódico científico secundário, mapeando sua literatura, divulgando-o e demonstrando sua importância para comunidade científica.

Devido ao considerável tempo demandado por esse tipo de pesquisa no campo bibliográfico, optamos por analisar apenas uma amostra do periódico PBCIB. Entretanto, fica registrada a necessidade de futuras incursões de pesquisadores que contemplem o periódico em sua totalidade, no intuito de otimizar seus serviços, proporcionando-lhe maior consistência, precisão e visibilidade.

\section{REFERÊNCIAS}

BARDIN, L. Análise de Conteúdo. 3. ed. Lisboa: Edições 70, 2004.

BIOJONE, M. Os periódicos científicos na comunicação da ciência. São Paulo: EDUC- FAPESP, 2003.

DIAS, G. A. Periódicos científicos brasileiros na área de Ciência da Informação. 2003, 223 f. Tese (Doutorado em Ciências da Comunicação) - Escola de Comunicação e Artes da Universidade de São Paulo-USP. São Paulo, 2003.

FREIRE, G. H. de A. et al. Uso do SEER para formatação de serviço de resumos: revista pesquisa brasileira em Ciência da Informação e Biblioteconomia. Ciência da Informação, Brasília, v. 36, n. 3, p. 83-88, set./ dez. 2007.

GIL, A.C. Métodos e técnicas de pesquisa social. 5. ed. São Paulo: Atlas, 1999. $206 \mathrm{p}$.

LATOUR, B. Ciência em ação: como seguir cientistas e engenheiros sociedade a fora. São Paulo: UNESP, 2000.

LEMOS, A. A. B. de. Periódicos eletrônicos: problema ou solução? In: ENCONTRO NACIONAL DE EDITORES CIENTíFICOS, 10., 2005, São Pedro. [Trabalhos apresentados...] Disponível em: <http://www.briquetdelemos.com.br/ briquet/briquet_lemos7.htm> Acesso em: 26 maio 2006. 
LOURENÇO, C. V. Automação em bibliotecas: análise da produção via Biblioinfo. In: Witter G. P. (Org.) Produção Científica. Campinas: Alínea, 1997.

MACIAS-CHAPULA, C. A. O papel da informetria e da cienciometria e sua perspectiva nacional e internacional. Ciência da Informação, Brasília, v. 27, n. 2, p. 134-140, maio/ ago. 1998.

MÁRDERO ARELLANO, M. A.; SANTOS, R. dos; FONSECA, R. da. SEER: disseminação de um sistema eletrônico para editoração de revistas científicas no Brasil. Arquivística.net, Rio de Janeiro, v. 1, n. 2, p. 75-82, jul./ dez. 2005.

MEADOWS, A. J. Os Periódicos científicos e a transição do meio impresso para o eletrônico. Revista de Biblioteconomia de Brasília, v. 25, n. 1, p. 5-14, 2001.

MEIRELLES, R. F. O sistema eletrônico de editoração de revistas (SEER) e sua adoção em periódicos brasileiros. Arquivística.net, Rio de Janeiro, v. 2, n. 2, p. 197-207, ago./ dez. 2006.

ORNELAS, M. L.; ARROYO, G. C. Las revistas acadêmicas electrónicas en Internet. Revista Mexicana de Comunicación. Disponível em: <http://www. mexicanadecomunicacion.com. $m x / T a b l e s / R M C /$ rmc83/revistas. $h$ tml> Acesso em 29 mar. 2006.

PINHEIRO, L. V. R. Fontes ou recursos de informação: categorias e evolução conceitual. Pesquisa Brasileira em Ciência da Informação e Biblioteconomia, v. 1, n. 1, 2006. Disponível em: <http://revista.ibict.br/pbcib/index.php/pbcib/article/ view/210/3>Acesso em: 16/3/2007.

SOUZA, Alexandre Pereira. Mapeamento da produção científica do periódico eletrônico PBCIB: um estudo da recuperação da informação nos resumos publicados entre 2006-2008. 2010. 91f. Monografia (Graduação em Biblioteconomia) - Universidade Federal da Paraíba. João Pessoa, 2010.

STUMPF, I. R. C. Passado e futuro das revistas científicas. Ciência da Informação, Brasília, v.25, n.3, 1996.

ZIMAN, J. Conhecimento público. Belo Horizonte: Itatiaia; São Paulo: EDUSP, 1979.

\section{Title}

Journal Pesquisa Brasileira em Ciência da Informação e Biblioteconomia - PBCIB: a thematic mapping in the light of scientific content analysis

\section{Abstract}

The paper presents the mapping of the scientific output of the electronic journal Pesquisa Brasileira em Ciência da Informação e Biblioteconomia - PBCIB, by analyzing the abstracts published between 2006 and 2008. This article is based on a previous study 
entitled "Mapping of Scientific Production of Periodic Electronic PBCIB. The research followed a sequential mixed method approach (exploratory-descriptive). Bardin's technique was applied for the content analysis of a total of 194 indexed abstracts which were classified according to their respective themes and were later categorized to score the characteristics and scope of the journal. The findings state that PBCIB journal performs its function as a periodic of reference, by directing its users to emerging contents in information science and librarianship fields. It presents suggestions to help the optimization of the journal, such as a fully analysis of the journal with the goal of providing greater consistency, accuracy and visibility in the academic community.

\section{Key-words}

Scientific communication. Electronic Journals. Scientific production. Information Science. Librarianship.

\section{Titulo}

Revista Pesquisa Brasileira em Ciência da Informação e Biblioteconomia - PBCIB: un mapeamiento temático de la producción científica a la luz del Análisis de Contenido

\section{Resumen}

Se refiere al mapeamiento temático de la producción científica registrada en la revista electrónica de referencia Pesquisa Brasileira em Ciência da Informação e Biblioteconomia - PBCIB, a partir de las informaciones contenidas en los resúmenes publicados entre 2006-2008. El artículo se origino de un trabajo titulado Mapeamiento de la producción científica de la revista electrónica PBCIB. Para la realización de la investigación fue hecha la identificación temática de los 194 resúmenes indexados a partir de los ejes temáticos de la revista. Finalizado esa etapa de los resúmenes fueron dispuestos en un corpus de análisis y categorizados de acuerdo con sus respectivas temáticas. La investigación se define por su carácter exploratorio y descriptivo con enfoque cualitativo y cuantitativo, utilizando la técnica de análisis de contenido para mapear los resúmenes y categorizarlos, señalando así las características y el alcance de la revista. Según la encuesta, el PBCIB cumple su función de referencia periódica direccionando sus usuarios al contenido en las áreas de la Ciencia de la Información y Biblioteconomía, ofreciendo un servicio relevante para las áreas cuyos campos de investigación vienen presentando creciente producción científica en el Brasil. Se presentan sugestiones que peuden contribuir a la optimización de los servicios ofrecidos, sugiriendo un análisis completo del periódico con el objetivo de proporcionar mayor consistencia, precisión y visibilidad de la revista en la comunidad académica.

\section{Palabras-clave}

Producción científica. Comunicación científica. Periódicos electrónicos. Analisis de Contenido. Ciencias de la Información. Bibliotecología.

Recebido em: 07/07/2010

Aceito em: 11/02/2011 